\title{
II.2. Modelos desenvolvidos por comentadores
}

Esta seção, e subseções, exibe parte consideravelmente importante do "estado da arte" a respeito dos diagramas para as classificações de signos de Peirce. Ela complementa o capítulo anterior, com diagramas desenvolvidos por alguns dos principais estudiosos da semiótica de Peirce. ${ }^{32}$ A primeira seção apresenta diagramas que foram concebidos especificamente para modelar a divisão em dez classes, conforme proposta no "Syllabus", de 1903. O diagrama 10cubes oferece uma alternativa, dinâmica, aos modelos estáticos aqui expostos. A segunda seção apresenta modelos mais flexíveis, que podem ser aplicados a mais de um tipo de classificação. O diagrama 3N3, apresentado na Seção II.3.3.2, também é um modelo deste tipo, com a vantagem de ser interativo.

\section{II.2.1. Modelos para dez classes de signos}

Os diagramas de M. Balat

M. Balat faz parte de um grupo de semioticistas ligados à Universidade de Perpignan, na França (outro expoente deste grupo é R. Marty, cujos diagramas são apresentados na próxima seção). ${ }^{33}$ Eles, especialmente durante a década de 1980, se dedicaram ao estudo das estruturas e relações presentes nas classificações sígnicas de Peirce. Balat (1990) apresenta três modelos, aos quais nos referimos aqui como "diagrama triangular" (BALAT 1990: 81, Figura 26), "diagrama quadrado" (BALAT 1990: 85, Figura 27) e "diagrama 3D" (BALAT 1990: 86, Figura 28). Este último baseou a criação do diagrama dinâmico 10cubes (Seção II.3.3.1).
Eta abordagem não pretende, evidentemente, ser exaustiva. Diversas tentativas de modelagem diagramática das classificações não foram incluídas nesta seção e subseções.

Outros expoentes incluem Antony Jappy e Joelle Rethoré. 
Figura 26. "Diagrama triangular" de M. Balat para as dez classes de signos de Peirce (BALAT 1990: 81).
Figura 27. "Diagrama quadrado" de M. Balat para as dez classes de signos de Peirce (BALAT 1990: 85).

Figura 28. "Diagrama 3D" proposto por Michel Balat (1990: 86).
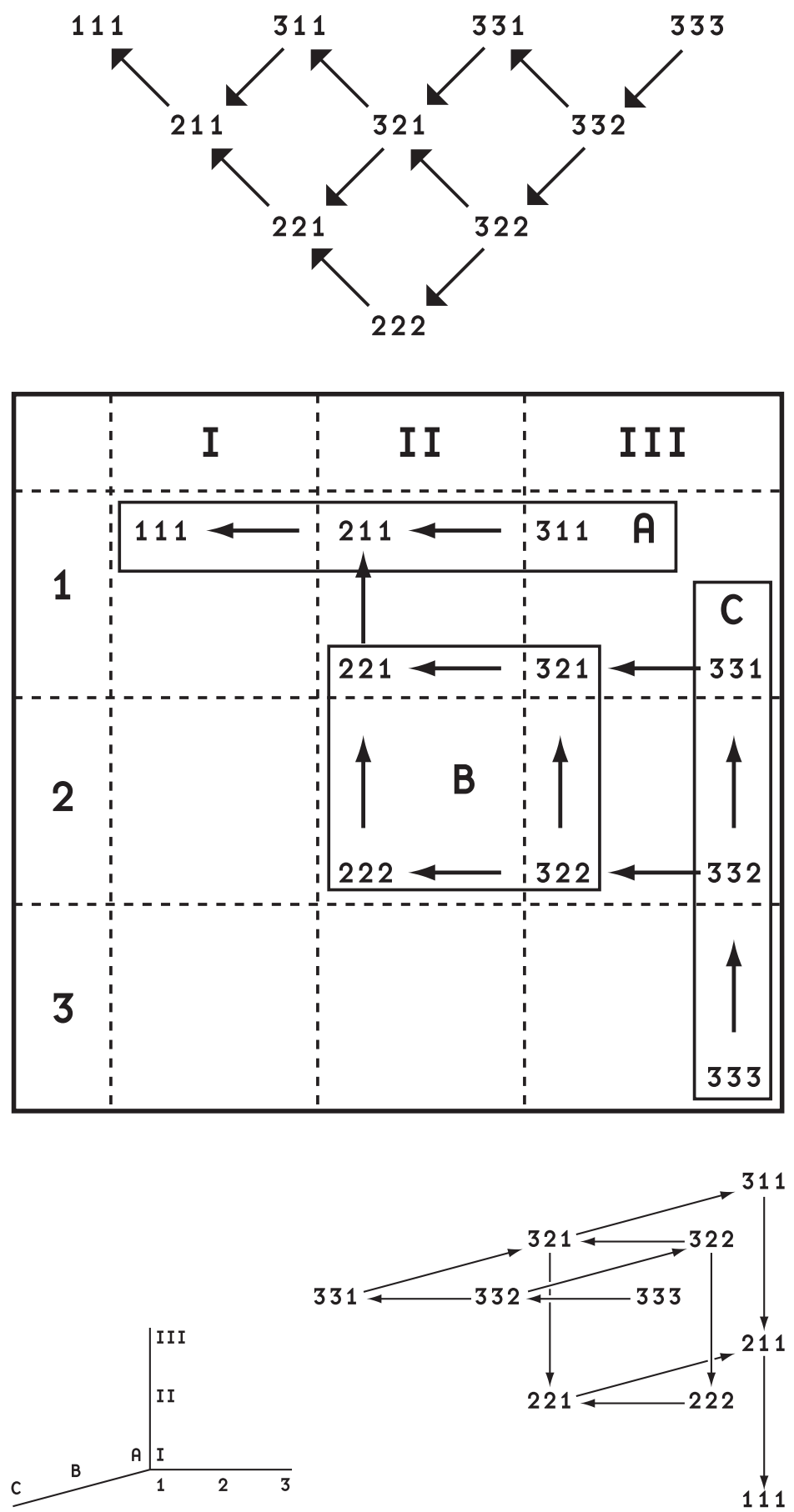
Nos três diagramas, a notação para as dez classes é a mesma adotada aqui (sequências de algarismos 1, 2 e 3). Existem conexões orientadas (flechas) ligando certas classes. Estas conexões são exatamente as mesmas nos três diagramas (conectam as mesmas classes, apontando nas mesmas direções), embora o arranjo dos diagramas seja bastante diferente. O diagrama quadrado (Figura 27) e o diagrama 3D (Figura 28) adotam a mesma convenção para representar as modalidades tricotômicas que formam as classes: algarismos romanos (I, II, III) para as modalidades da primeira; letras $(\mathrm{A}, \mathrm{B}, \mathrm{C})$ para as modalidades da segunda; e algarismos arábicos $(1,2,3)$ para as modalidades da terceira tricotomia.

Balat (1990: 86) descreve três tipos de relação representados por conexões orientadas - incorporação, instanciação e regência -, mas não chega a definir o significado de todas elas. Ele faz referência somente às flechas horizontais encontradas no diagrama quadrado (Figura 27), agrupadas segundo as colunas (I, II e III) nas quais se encontram. Segundo ele, as flechas da coluna I significam incorporação, da coluna II, instanciação e da coluna III, regência.

Comparando a posição de Balat com a descrição das relações entre classes indicadas por Peirce no "Syllabus" (ver Tabela 1, Seção I.1.3), Serson (1997: 134-136) interpreta diferentemente estas conexões. Ele as divide em relações de "instanciação" (setas horizontais) e de "envolvimento" (setas verticais), notando que existe um problema - "'anomalias' ou exceções a uma clara distinção entre instanciação e envolvimento" (SERSON 1997: 136) - com relação às setas que unem as classes 333 e 332, e as classes 211 e 111. Entre as duas primeiras (333/332), segundo ele, há uma relação de instanciação que no diagrama aparece como uma seta vertical. Entre as outras duas (211/111), ao contrário, uma relação de envolvimento está representada no diagrama por uma flecha horizontal. Serson, aparentemente, não percebeu que no diagrama triangular de Balat (1990: 81, Figura 26) tais "anomalias" não ocorrem, sendo possível dizer que, neste, todas as setas que apontam para baixo representam relações de instanciação, e todas aquelas que apontam para o alto representam relações de envolvimento.

Se o diagrama triangular (Figura 26) destaca-se pela facilidade e coerência na interpretação de suas conexões orientadas, a principal vantagem do diagrama quadrado (Figura 27) é apresentar, de forma clara, os diversos subgrupos que existem dentro das dez classes de signos. Sabendo que algarismos romanos correspondem às modalidades da primeira, letras correspondem às modalidades da segunda e algarismos arábicos correspondem às modalidades da terceira tricotomia, é fácil notar a presença de nove subgrupos: 
Qualisignos (primeira coluna, I)

Sinsignos (segunda coluna, II)

Legisignos (terceira coluna, III)

Ícones (conjunto delimitado pelo quadrilátero A)

Índices (conjunto delimitado pelo quadrilátero $\mathrm{B}$ )

Símbolos (conjunto delimitado pelo quadrilátero C)

Remas (primeira linha, 1)

Dicentes (segunda linha, 2)

Argumentos (terceira linha, 3)

O diagrama dinâmico 10cubes, apresentado na Seção II.3.4 pode ser observado como uma tentativa de recuperar estas propriedades heurísticas a partir de uma interface baseada no diagrama 3D (Figura 28), utilizando estratégias de modelagem apontadas no Capítulo II.3.

\section{Os diagramas de F. Merrell}

Merrell fez diversos diagramas para as dez classes de signos de Peirce. Entre eles, há uma tabela que mostra as combinações entre modalidades tricotômicas que geram as dez classes (MERRELL 1996: 8), adaptada na Figura 10. O primeiro diagrama apresentado nesta seção (MERRELL 1991: 17, Figura 29) refere-se às dez classes e suas possíveis relações. O segundo (MERRELL 1997: 298-299, Figura 30) exibe relações entre as dez classes e os três tipos de hipoícone.

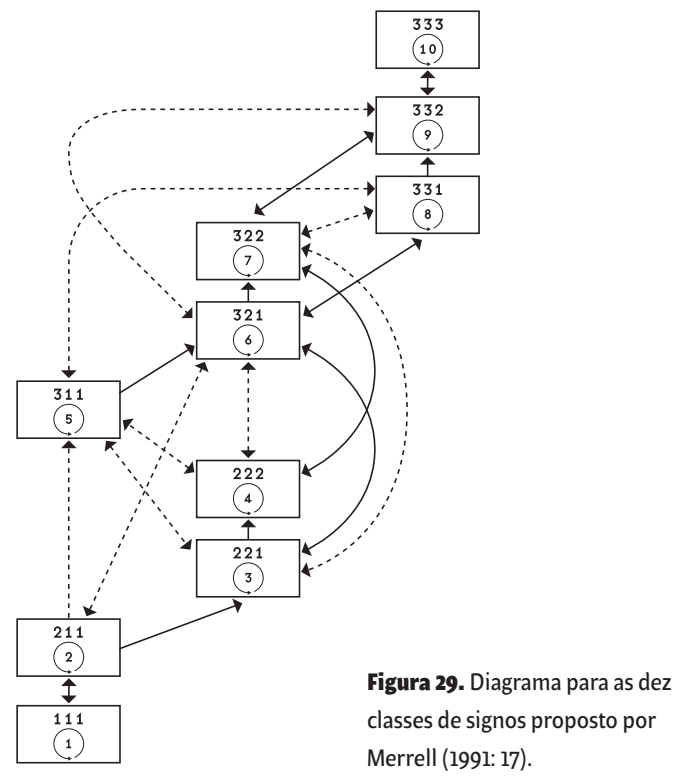


A Figura 29 é uma versão simplificada do diagrama proposto por Merrell (1991: 17). A versão original contém letras e outros recursos para facilitar a referência a exemplos mencionados no artigo (MERRELL 1991). A versão reproduzida aqui preserva a estrutura de relações entre as classes, que é o aspecto mais relevante da proposta de Merrell. As classes, identificadas através da mesma notação adotada neste livro, estão divididas em três colunas, de acordo com o subgrupo, definido pela modalidade da segunda tricotomia (ícone, índice, símbolo), ao qual pertencem.

As conexões orientadas que aparecem neste diagrama são, segundo Merrell (1991: 20), "operadores" que podem ser divididos em quatro grupos, de acordo com seu tipo e direção. Conexões contínuas representam "caminhos normais de transmutação sígnica", enquanto conexões segmentadas representam caminhos "anormais". Conexões unidirecionais apontam caminhos de "geração" ou "evolução" de signos mais simples para signos mais complexos, enquanto conexões bidirecionais significam que um caminho de "desenvolvimento" pode, na direção contrária, significar um provável caminho de "subdivisão" ou "degeneração" (MERRELL 1991: 20).

Segundo Merrell (1991), relações entre classes, como aquelas que aparecem nos diagramas de Balat (Figuras 26, 27 e 28), podem ser entendidas como "relações de geração" dentro do processo da semiose, e limitam-se à descrição de propriedades de signos mais gerais. A estrutura proposta na Figura 29, por outro lado, modela os caminhos de "degeneração" semiótica.

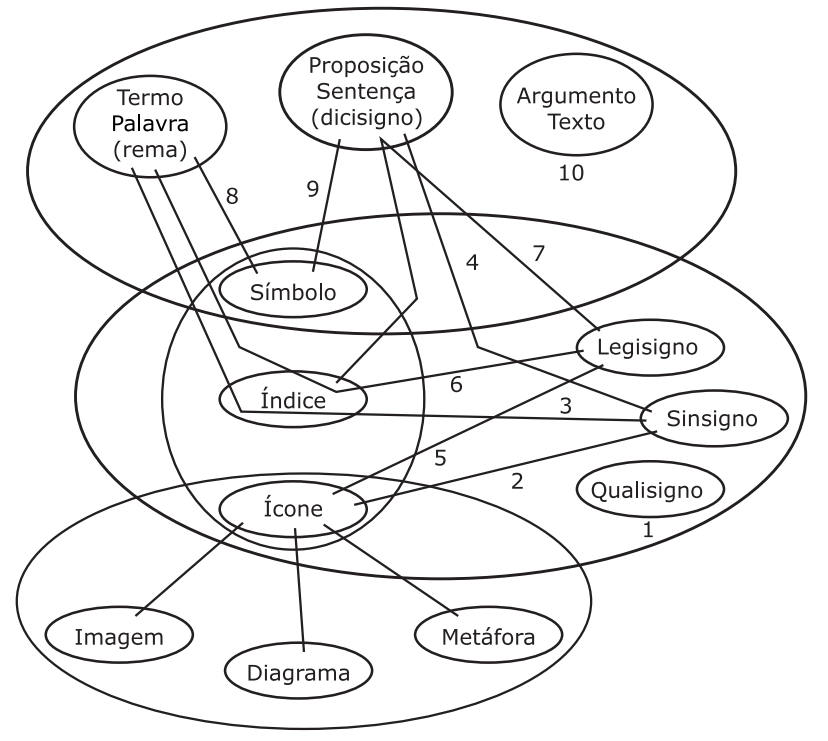

Figura 30. Diagrama relacionando as dez classes de signos com os três tipos de hipoícone proposto por Merrell (1997: 298-299). 

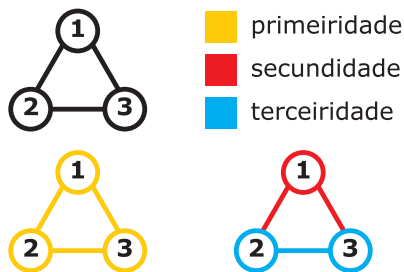

1

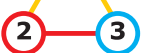

(2)

(1)
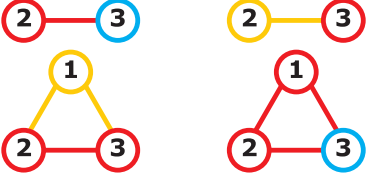

1

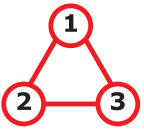

2
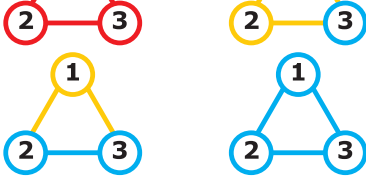

Figura 31. Modelo para as dez classes de relações triádicas proposto por Olsen (1999: 8).
O segundo diagrama (MERRELL 1997: 298-299, Figura 30) coloca em foco a estrutura e não as relações entre as dez classes, mostrando-as como conjuntos constituídos a partir das modalidades tricotômicas. Assim como na Figura 10 (I.1, baseada em MERRELL 1996: 8), as classes são identificadas com números de 1 a 10, e as modalidades agrupadas conforme a tricotomia à qual pertencem. Além das três grandes elipses que separam, por tricotomia, as modalidades, vemos uma quarta elipse que abrange a modalidade "ícone" e contém os três tipos de hipoícones (imagem, diagrama, metáfora). Embora esta questão não fique clara no texto, isso sugere que, para Merrell, as classes que contêm esta modalidade (icônica) poderiam ser subdivididas em classes hipoicônicas imagéticas, diagramáticas e metafóricas.

\section{Outros modelos para as dez classes}

Outros modelos para as dez classes foram propostos por Olsen (1999, Figuras 31 e 32), Hoffman (2001, Figura 33), Amadori (2001: 34, Figura 24). Os modelos de Olsen e Amadori utilizam cores. Os modelos de Amadori e Hoffman utilizam cubos representados em um espaço tridimensional para localizar as classes.

Olsen (1999) propõe uma notação para as classes de signos. Na Figura 31 vemos esta notação, composta por três correlatos (representados pelos círculos contendo os números 1 , 2 e 3) e suas relações (conexões entre os círculos). Segundo Olsen, esta estrutura, composta apenas por relações diádicas entre correlatos, combinada com um trio de cores que corresponde às categorias (primeiridade, secundidade e terceiridade), é suficiente para modelar as "10 classes de relações triádicas" descritas por Peirce (OLSEN 1999: 8). A partir desta estrutura e de uma notação suplementar para as relações triádicas, Olsen chega a uma notação para as dez classes de signos descritas no "Syllabus" (Figura 32). Como notamos, a conclusão de Olsen é que a lógica da divisão dos signos exposta no "Syllabus" permite a existência de seis tipos diferentes de qualisignos (111), e três tipos diferentes de sinsignos icônicos (211), sinsignos indexicais remáticos (221) e sinsignos dicentes (222).

Os modelos de Hoffmann (2001, Figura 33) e Amadori (2001: 34, Figura 34) são bastante similares e suas estruturas internas se assemelham àquela indicada no diagrama $3 \mathrm{D}$ de Balat (Figura 28). As relações de proximidade entre os cubos, que nestes diagramas representam as classes, são exatamente 
as mesmas, embora, em comparação com o diagrama 3D de Balat, o conjunto de cubos do diagrama de Amadori pareça ter sido girado, e o de Hoffmann, além disso, espelhado.

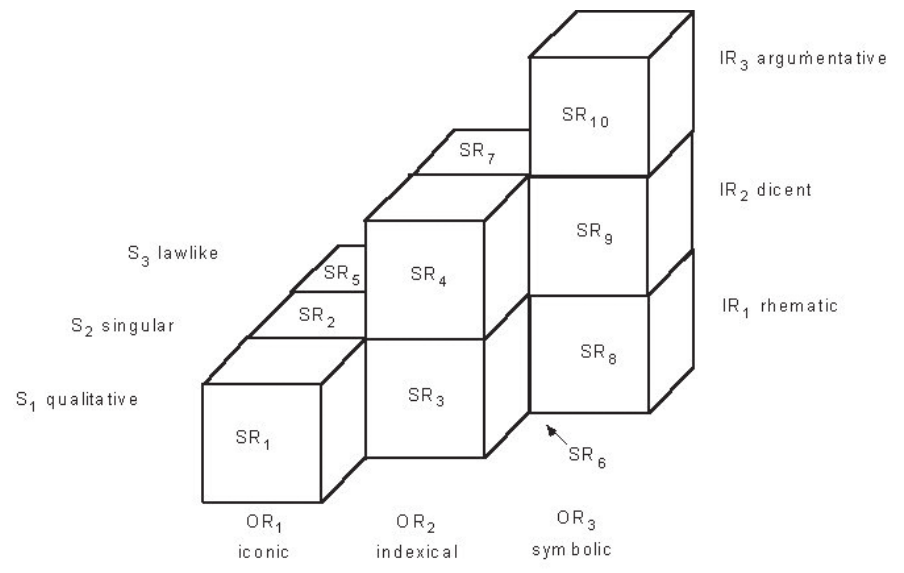

Figura 33. Modelo tridimensional para as dez classes de signos proposto por Hoffmann (2001).

O modelo de Hoffmann (2001, Figura 33) não utiliza cores, e as classes são identificadas por uma numeração de 1 a 10 colocada sob a sigla $S R$ (para sign-relation) em cada cubo. Ao lado e abaixo do conjunto, vemos as siglas $S$ (para sign itself), OR (para object relation) e IR (para interpretant relation), acompanhadas pelos números 1,2 , ou 3, para indicar as modalidades tricotômicas representadas em cada um dos eixos do diagrama.

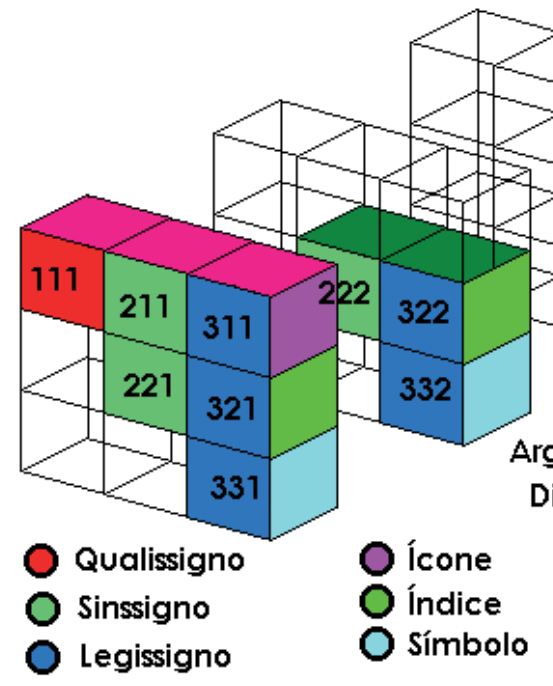

(2) (3) (2) (3) (2) (3) (2) (3) (2) (3) (2) (3) (2) (3) (2) (3) (2) (3)

(2) (3) (2) (3) (2) (3)

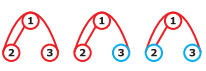

(2) (3)

(2) (3)

(2) (3)

(2) (3)

(2) (3)

(2) 3

Figura 32. Notação para as dez classes de signos descritas no "Syllabus", segundo o modelo proposto por Olsen (1999: 18). De cima para baixo: na primeira linha, seis tipos de qualisignos (111); nas três linhas seguintes, três tipos de sinsignos icônicos (211), três tipos de sinsignos indexicais remáticos (221) e três tipos de sinsignos dicentes (222); nas outras, notações para as classes remanescentes (311, 321, 322, 331, 332, 333).
Figura 34. Modelo tridimensional para as dez classes de signos proposto por Amadori (2001: 34). 
Figura 35. Diagrama para as dez classes de signos proposto por Marty (adaptado de MARTY 1982a: 178, 1990: 171).
No modelo de Amadori (2001: 34, Figura 34), as classes estão identificadas por sua notação numérica habitual (a mesma adotada aqui) e por um sistema de cores. Como acompanhamos na legenda abaixo do diagrama, as modalidades de primeiridade estão representadas por três tons do espectro vermelho, as modalidades de secundidade por tons de verde e as modalidades de terceiridade por tons de azul.

\section{II.2.2. Modelos para várias divisões de signos}

Os modelos de R. Marty

Em seu livro L'algèbre des signes (MARTY 1990) e em diversos artigos (MARTY 1982a e 1982b), Marty apresenta um tratamento matemático das classificações, baseado no que chama de "faneroscopia analítica" (MARTY 1990: 143). Por meio deste tratamento, ele não apenas demonstra matematicamente a construção das classes, mas também "deriva" uma série de relações entre elas.

Ao aplicar o mesmo tratamento às dez e às 28 classes, Marty obtém diagramas apresentados nas Figuras 35 e 36. Em ambos, as classes são apresentadas em uma estrutura hierárquica (MARTY 1982: 178) em que cada classe implica a presença das classes que estão abaixo. As conexões segmentadas no diagrama para as dez classes (Figura 35) indicam relações de um tipo especial (réplicas) entre legisignos e sinsignos.

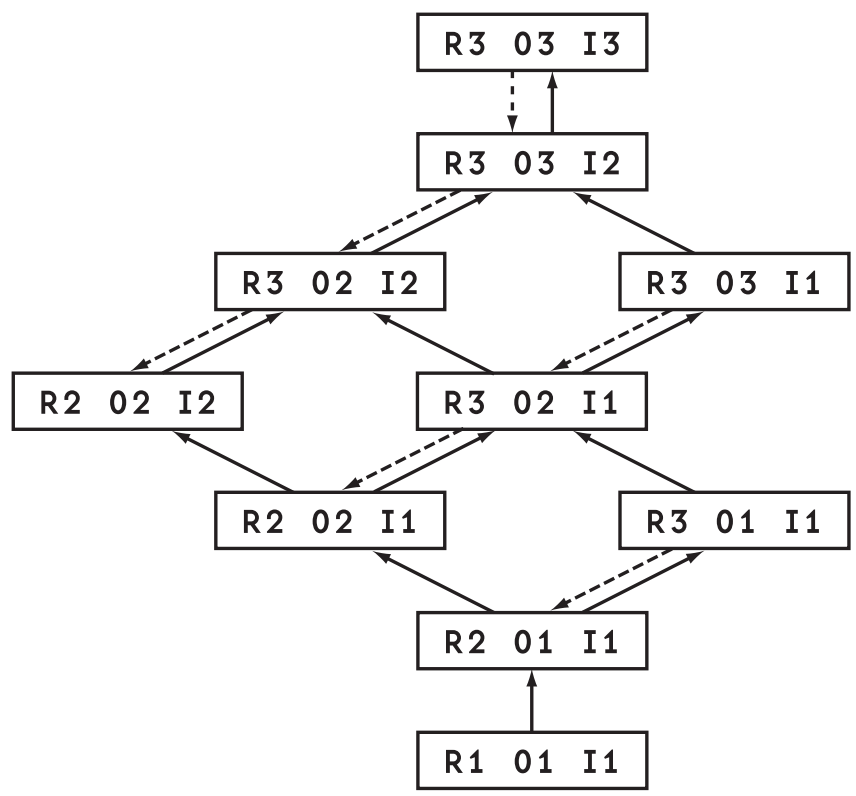




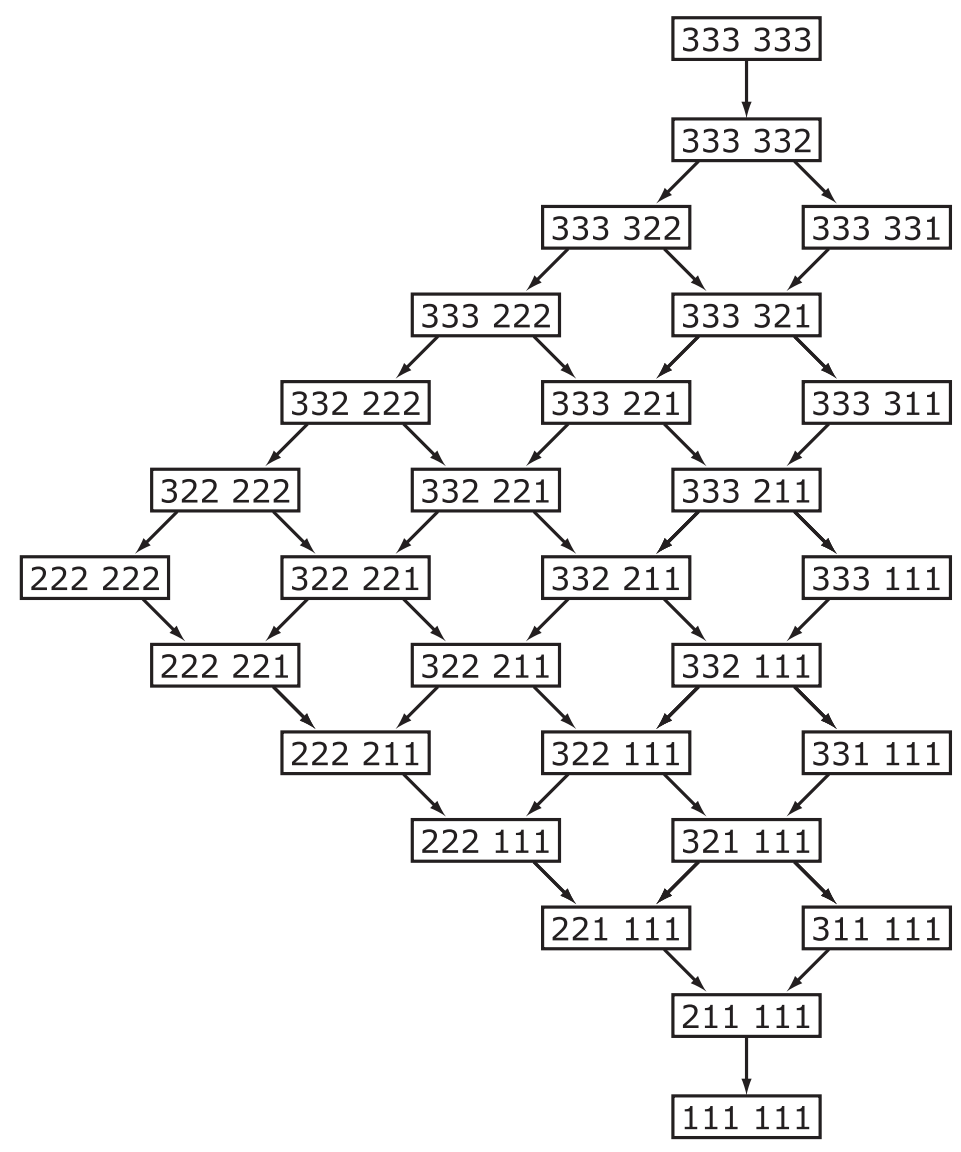

Para Marty, este tratamento permite estabelecer relações entre as dez e as 28 classes de signos (MARTY 1990: 225-228). A Figura 37 reproduz um diagrama, de estrutura similar à da Figura 35, no qual Marty inclui uma numeração que indica quais são as classes que, dentro da divisão em 28 classes, correspondem a cada uma das dez classes de signos. Ele não aplica o mesmo tratamento às 66 classes, como esperaríamos, pois acredita que as classificações, além da divisão em 28 classes, são redundantes (MARTY 1990: 228-235).
Figura 36. Diagrama para as 28 classes de signos proposto por Marty (adaptado de MARTY 1982b: 10, 1990: 224). 
Figura 37. Diagrama onde as 28 classes de signos são apresentadas dentro da estrutura hierárquica das dez classes, proposto por Marty (adaptado de MARTY 1990: 228).
Figura 38. Estrutura diagramática para modelar diversas classificações de signos proposta por Maróstica (adaptado de MARÓSTICA 1992: 130-132).

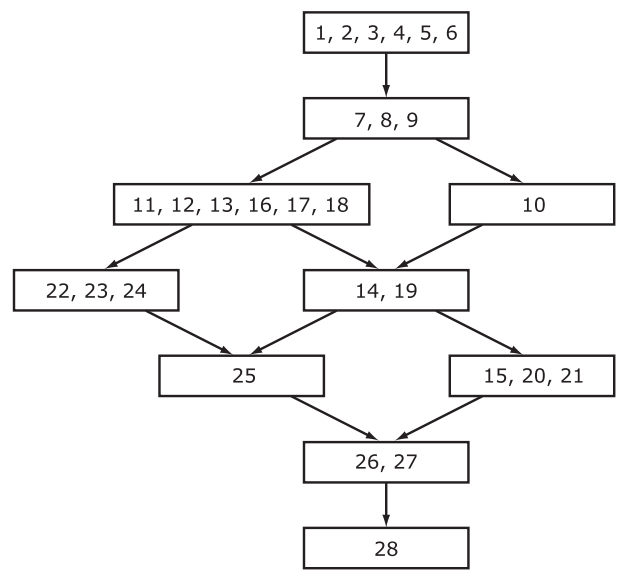

\section{O modelo de A. Maróstica}

Ao observar uma relação entre a quantidade de tricotomias e o número de classes nas divisões de signos descritas por Peirce, Maróstica (1992) propõe um tratamento das classificações baseado em equações combinatórias. Os resultados numéricos obtidos equivalem aos obtidos por meio da equação de Weiss e Burks (1945), $(n+1)(n+2) / 2$, onde $n$ representa o número de tricotomias. Entre os aspectos mais interessantes desta abordagem, encontra-se a proposta de uma estrutura diagramática, baseada no diagrama de Welby (Figura 22), capaz de conter qualquer número de classes (Figura 38). Esta estrutura é bastante similar àquela utilizada no diagrama dinâmico 3N3, apresentado na Seção II.3.5.

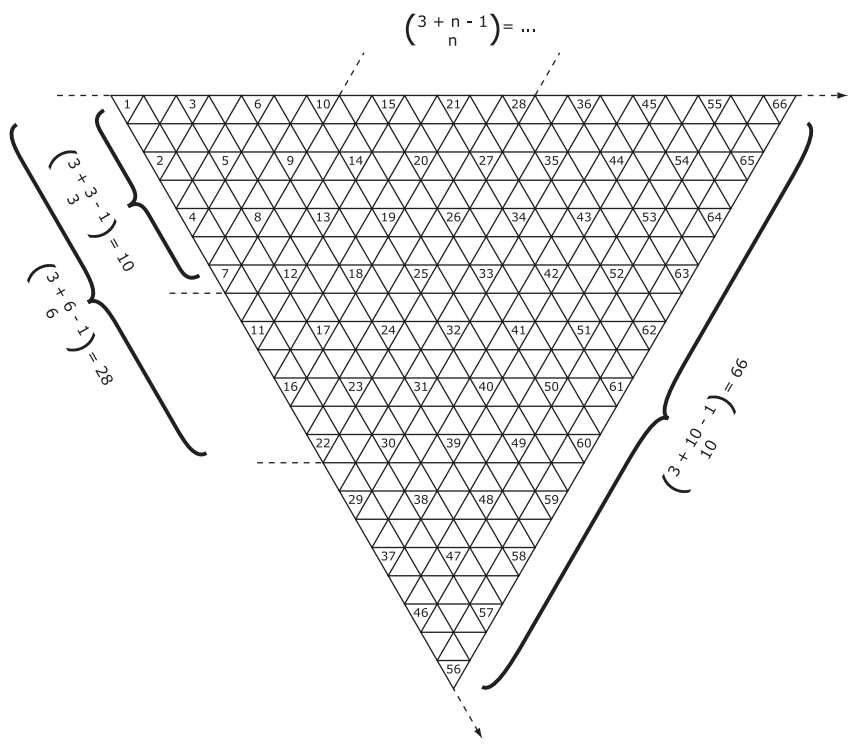




\section{Outros modelos para 66 classes}

Modelos alternativos para a representação de 66 classes de signos foram propostos por Vinicius Romanini (2006, Figura 39) e Priscila Borges (2010, Figura 40). Romanini descreve seu modelo como uma "tabela periódica das classes de signos" (ROMANINI 2006: 155). A nomenclatura utilizada por ele, entretanto, para descrever as classes, bem como as regras usadas para obtê-las, difere em vários aspectos daquelas adotadas por outros especialistas. Borges propõe um diagrama que chama de signtree (BORGES 2010: 49). A autora demonstra como é possível visualizar dez classes de signos descritas por Peirce como agrupamentos das 66 classes representadas em seu diagrama (BORGES 2010: 143, Figura 40).

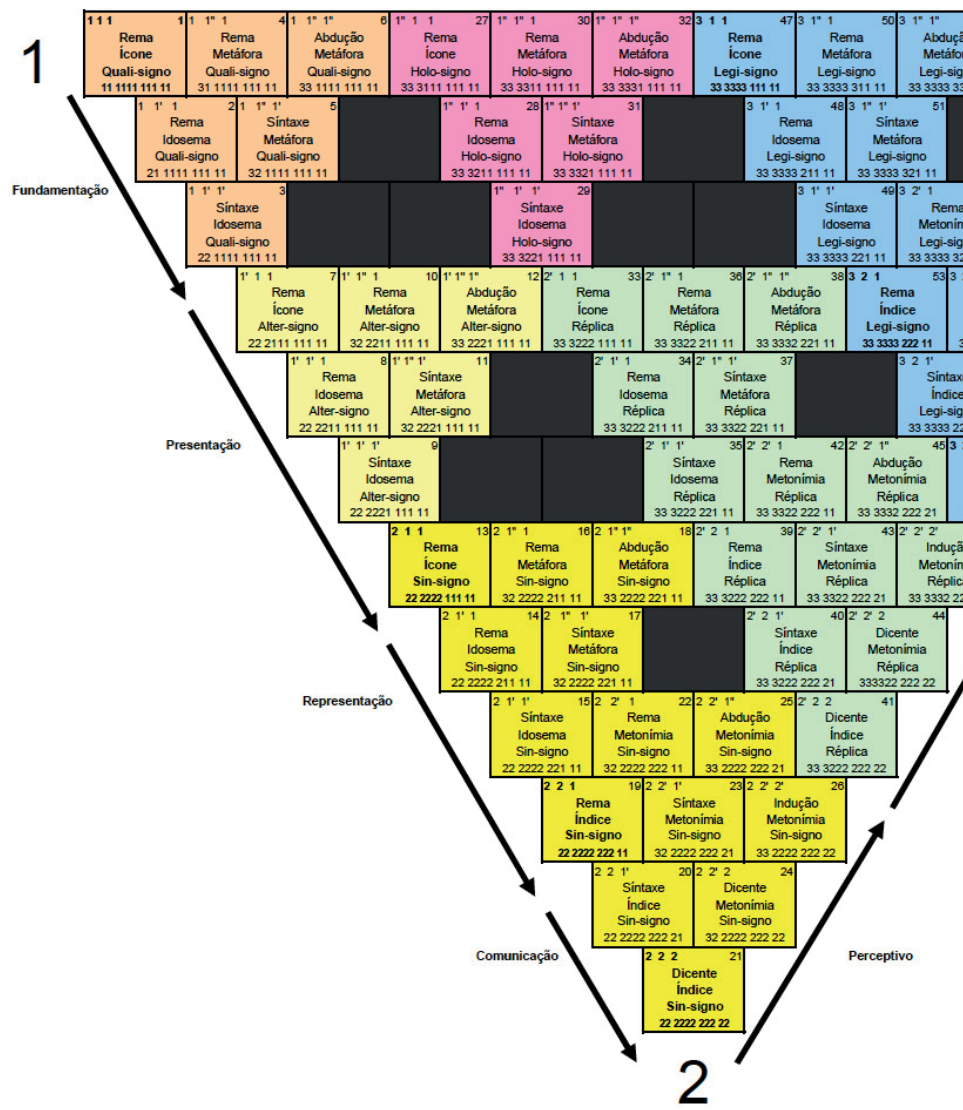

Figura 39. "Tabela periódica das classes de signos" proposta por Romanini (2006: 155). 
Figura 40. Identificação de grupos correspondentes às dez classes dentro do modelo signtree, proposto por Borges (2010: 143).

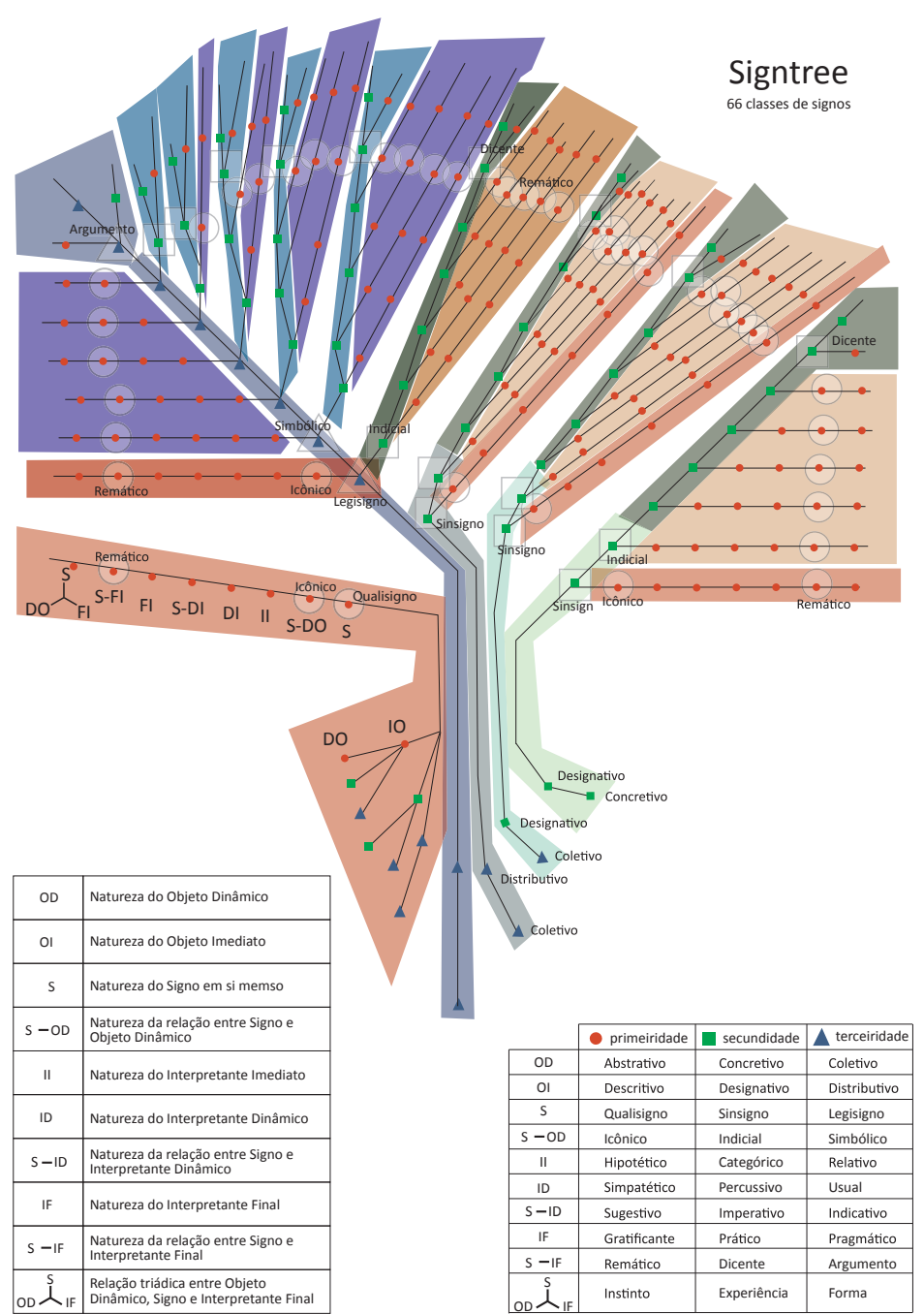

O próximo capítulo discute algumas limitações encontradas nos modelos discutidos e propõe novas estratégias que podem ser utilizadas na construção de diagramas para as classes de signos de Peirce. 